\title{
Rapid Detection of Trace 1,4-Dichlorobenzene Using Laser Mass Spectrometry
}

\author{
Lei Ding, Jing Ma, Haiyang Zheng. Li Fang, ${ }^{*}$ Weijun Zhang, Dukhyeon Kim. ${ }^{\dagger}$ and Hyungki Cha ${ }^{+*}$
}

Laboratory of Environmental Spectroscopy, Anhui Institute of Optics \& Fine Mechanics, The Chinese Academy of Sciences, Hefei 230031, China. "E-mail: fangli@aiofm.ac.cn "Quantum Optics Laboratory, Korea Atomic Energy Research Institute, Daejeon 305-353, Korea. "E-mail: hkcha@kaerire.kr Received February 13, 2006

\begin{abstract}
The 1+1 two-photon Resonant Enhanced Multiphoton Ionization (REMPI) spectra of 1,4-dichlorobenzene was obtained from $240 \mathrm{~nm}$ through to $250 \mathrm{~nm}$ on a laser mass spectrometer. Special care was taken to build up a heatable sample inlet system suitable for detecting a trace semi-volatile organic compound and reducing the memory effort on the inner wall of the inlet system. The detection limits of 1,4-dichlorobenzene in ppbV/V concentration range at certain wavelengths are presented.
\end{abstract}

Key Words : Laser mass spectrometry, Resonance-enhanced multiphoton ionization, Time of flight mass spectrum, 1,4-Dichlorobenzene

\section{Introduction}

Many trace pollutants are emitted by the combustion processes taking place in motorized vehicles or industrial incinerators, one of which is 1,4-dichlorobenzene $(1,4-$ DCB). 1,4-DCB is a white or colorless crystalline solid with a characteristic penetrating odor at room temperature. It is widely used as an insect killer and space deodorizers. The presence of 1,4-DCB in the environment can be hazardous to humans. Exposure can damage the lungs, liver, kidneys, and blood cells. It is also reasonably anticipated to cause human carcinogen based on sufficient evidence of a carcinogenicity in experimental animals. About $95 \%$ of the environmental releases of $1,4-\mathrm{DCB}$ occurs during its use. EPA regulates the levels of $1,4-\mathrm{DCB}$ in drinking water. The highest level of 1,4-DCB allowed in drinking water is 0.075 parts of 1,4-DCB per 1 million parts of water $(0.075 \mathrm{ppm})$. The Occupational Safety and Health Administration (OSHA) has set a limit for $1,4-\mathrm{DCB}$ of 75 ppm (75 parts of 1,4-dichlorobenzene per 1 million parts of air) in the workplace. Many studies show that $1,4-\mathrm{DCB}$ can also be used as a surrogate for monitoring numerous other toxic chlorinated hydrocarbons such as dioxins from incinerators. 1.2 An appropriate analytical tool for such trace substances is necessary in any case. The combination of a resonant multiphoton ionization (REMPI) and a time-of-flight mass spectroscopy (TOFMS) is a promising method for a chemical analysis and an on-line trace detection. ${ }^{3-7}$ To reduce the condensation effects at room temperature, a special heatable sample inlet system with an effusive nozzle was constructed in our lab to introduce a semi-volatile compound into the ionization region of TOFMS. In the experiment, different concentrations of a sample were prepared and analyzed. The relation between the jon current of $\mathrm{C}_{6} \mathrm{H}_{4}{ }^{35} \mathrm{Cl}_{2}{ }^{+}(\mathrm{M}=146)$ and the sample concentration was close to a linear one in the ppmV/V range, which led to a limit of detection (LOD) of $125 \mathrm{ppb}(\mathrm{S} / \mathrm{N}=2)$ for $1,4-$ dichlorobenzene at $248 \mathrm{~nm}$.

\section{Principles and Experimental Setup}

Laser mass spectrometry is a fast two-dimensional analytical technique which is the combination of two different analytical tools: Gas phrase UV spectroscopy and a time-offlight mass spectrometry (TOFMS). The two dimensions are provided by the REMPI process and a mass discrimination. Laser mass spectrometry is a promising way to fulfill the requirements of a rapid response time, high selectivity and sensitivity, and to realize the detection of target compounds from a complex mixture. Laser mass spectrometry is one of the most promising methods for a trace air pollutant analysis. The characteristic process of $1+1$ REMPI is shown in Figure 1: molecules absorb a photon and are excited into a UV-spectroscopic transition state. Absorbing a second photon subsequently ionizes these excited molecules. The left side of Figure 1 shows a one-color, two-photon REMPI excitation/ ionization scheme. This scheme can be used when the first

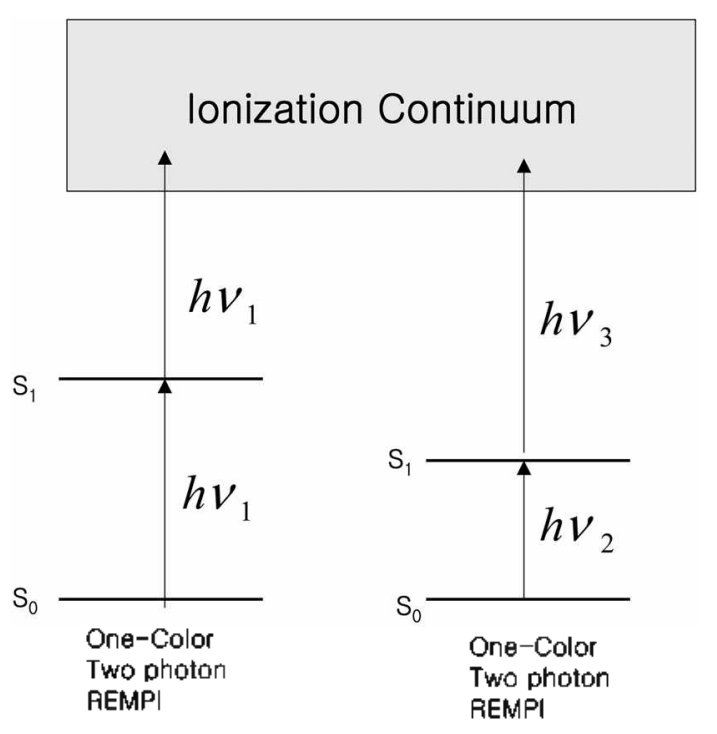

Figure 1. Diagram of the REMPI process. 
excited state $\left(S_{1}\right)$ lies more than half way to the jonization continuum. The right side of Figure I shows the two-color two-photon REMPI excitation/ionization scheme. This scheme can be used when the first excited state $\left(\mathrm{S}_{1}\right)$ lies less than half way to the ionization continuum.

In order to introduce a semi-volatile organic compound of a certain concentration into the ionization region of TOFMS we designed a special sample inlet system which could be heated. The schematic diagram of the sample inlet system for the experiment setup in our lab is illustrated in Figure 2. It consists of a special inlet system which could be heated, TOFMS, a laser source and a data acquisition and analysis system. The sample inlet system is a very important part. It consists of a sample cell, sample inlet tube and a temperature controller. The whole system is heated by heating tape.

A mixture of trace $1,4-\mathrm{DCB}$ in air near an atmospheric pressure was fed into a stainless stee] vacuum chamber through a $U$ tube. The jonization region of the TOFMS was of the classic dual field type described by Wiley and McLaren. The voltages of $+200 \mathrm{~V},-200 \mathrm{~V}$, and $-2400 \mathrm{~V}$ were maintained on the left, middle, and right acceleration plates respectively. The axis of the molecular beam was passed midway between the two left plates. The REPMI laser was focused on the intersection of the vertical molecular beam axis. Ionization light used in the experiment is produced by a tunable dye laser (TDL90, Quantel), which was pumped by the second hammonic of Nd:YAG (Brilliant $\mathrm{B}$, Quantel). The fundamental output of the dye laser (DCM) was frequency doubled and mixed with the $1.06 \mathrm{~mm}$, which produced a tunable wavelength ranging from $240 \mathrm{~nm}$ through to $250 \mathrm{~nm}$. The energy of each laser pulse was several millijoules with a pulse duration of around 6 ns.

The jons were received at the end of a $1.1 \mathrm{~m}$ long flight tube by a dual Multi-channe] Plates (MCP). The jon current signal was amplified and recorded through a transient recorder card (F9800) plugged into a personal computer which recorded the mass spectrum. In the experiment, each mass spectrum was averaged over 100 shots to increase the signal to noise ratio $\mathrm{S} / \mathrm{N}$.

\section{Results and Discussions}

The multiphoton ionization characteristic of $p$-dichlorobenzene $(1,4-D C B)$ in the range of $240-250 \mathrm{~nm}$ was studied first. The jonization potential of $1,4-\mathrm{DCB}$ is $8.95 \mathrm{eV}(72101$ $\mathrm{cm}^{-1}$ ). The origin of a transition from a ground state to the first excited state is at $279.7 \mathrm{~nm}^{8-10}$ At the laser wavelength used in our experiment, the molecules need at least to absorb two photons to become ionized, one photon for a resonant excitation and the other photon for an ionization. Study showed that no obvious peaks appear in the REMPI spectrum of $1,4-D C B$ from $240 \mathrm{~nm}$ through to $250 \mathrm{~nm}$. But the ionization of the molecules become very efficient, which is probably because the wavelength we used were a little far from the origin at $279.7 \mathrm{~mm}$.

Figure 3 shows the REMPI mass spectra of $1,4-D C B$ at three different exciting wavelengths with a constant laser energy intensity. It is obvious that the $1,4-\mathrm{DCB}$ can obtain a high ionization efficiency at $248 \mathrm{~nm}$. We found that the ions signal intensity become stronger from $240 \mathrm{~nm}$ through 250 nm when considering a practicality, we choose $248 \mathrm{~nm}$ as the ionization wavelength for the trace detection study of 1,4-DCB.

Figure 4 is the REMPI mass spectrum of 1,4-DCB at 248 $\mathrm{nm}$. As shown there are two kinds of ions: molecular ions $\mathrm{C}_{6} \mathrm{H}_{4}{ }^{35} \mathrm{Cl}_{2}{ }^{+}(\mathrm{m} / \mathrm{e}=146), \mathrm{C}_{6} \mathrm{H}_{4}{ }^{35} \mathrm{Cl}^{37} \mathrm{Cl}^{+}(\mathrm{m} / \mathrm{e}=148)$, $\mathrm{C}_{6} \mathrm{H}_{4}{ }^{37} \mathrm{Cl}_{2}{ }^{+}(\mathrm{m} / \mathrm{e}=150)$ and fragment ions $\mathrm{C}_{6} \mathrm{H}_{4}{ }^{35} \mathrm{Cl}^{+}(\mathrm{m} / \mathrm{e}=$ 111), $\mathrm{C}_{6} \mathrm{H}_{4}{ }^{37} \mathrm{Cl}^{+}(\mathrm{m} / \mathrm{e}=113), \mathrm{C}_{6} \mathrm{H}_{5}^{+}(\mathrm{m} / \mathrm{e}=77)$. These three species are the products of a dissociation of the molecular jons. From the relative natural abundances, due to the chlorine isotopes, the theoretical ratio for the masses 146 : $148: 150$ is $9.3: 6.1: 1$, and for the mass $111: 113$ is 1 : 0.32 . The signal intensities of the ions at these masses accord with the theoretical ratio.

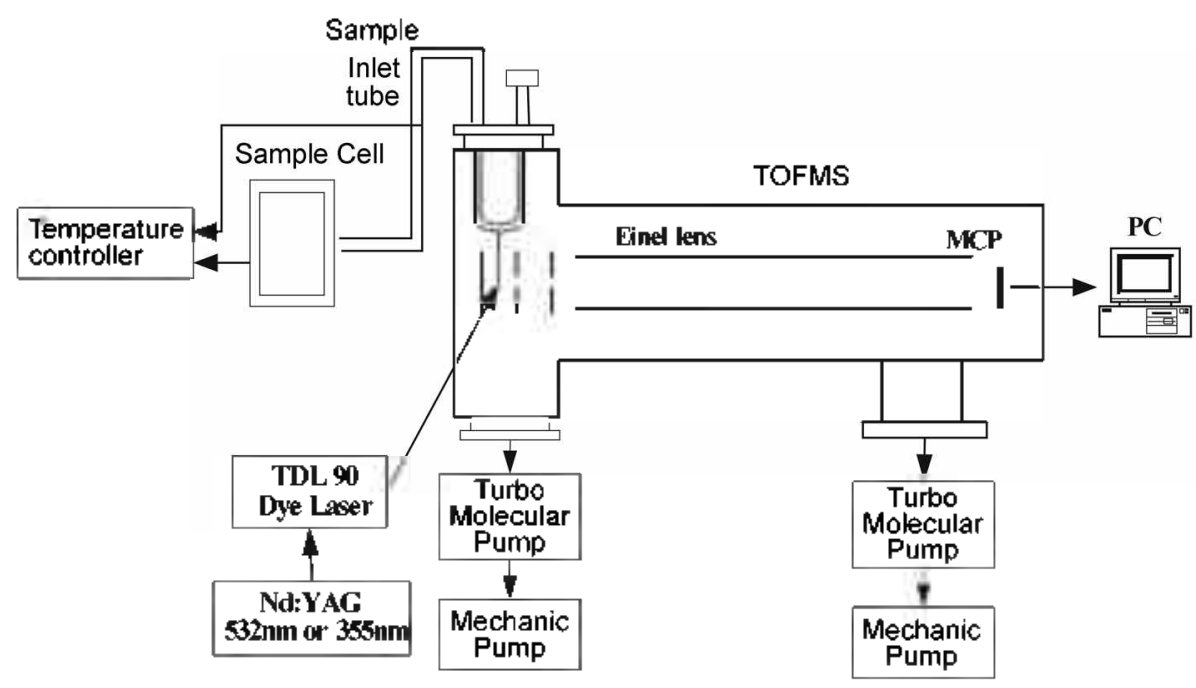

Figure 2. The scheme of experimental setup 


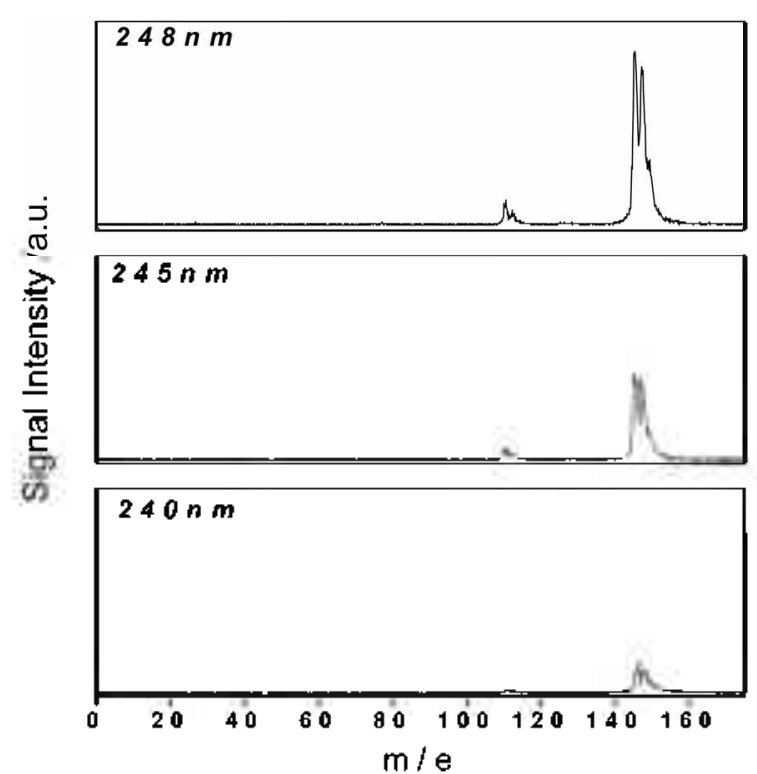

Figure 3. mass spectruin obtained from the ionization of 1,4-DCB at $248 \mathrm{~nm}, 245 \mathrm{~nm}$ and $240 \mathrm{~nm}$ respectively.

It is known that the signal intensity is relative to the sample concentration and the laser intensity. The function of the three variables can be illustrated by the following equation: $\mathrm{S}=\mathrm{c} \times \mathrm{n} \times \mathrm{f}(\mathrm{I})$, "S" is the signal intensity, " $\mathrm{n}$ " is the sample concentration, "f(I)" is the relationship between the laser energy and the signal intensity. So before we can obtain the relationship between the signal intensity and the sample concentration, we need to find the relationship between the signal intensity and the laser energy.

Figure 5 shows the relationship between the laser energy and the signal intensity of $\mathrm{CH}_{4}{ }^{35} \mathrm{Cb}^{+}$at $248 \mathrm{~nm}$. The relationship can be illustrated as $\ln S=$ nlnI. $n$ is the commonly used "power index", it indicates the photon number absorbed by the molecules from the initial state to the ionization continuum. in here is 1.52 less than 2 which is probably because of the saturated absorption of 1,4-DCB.

Based on the results we have achieved, we measured the

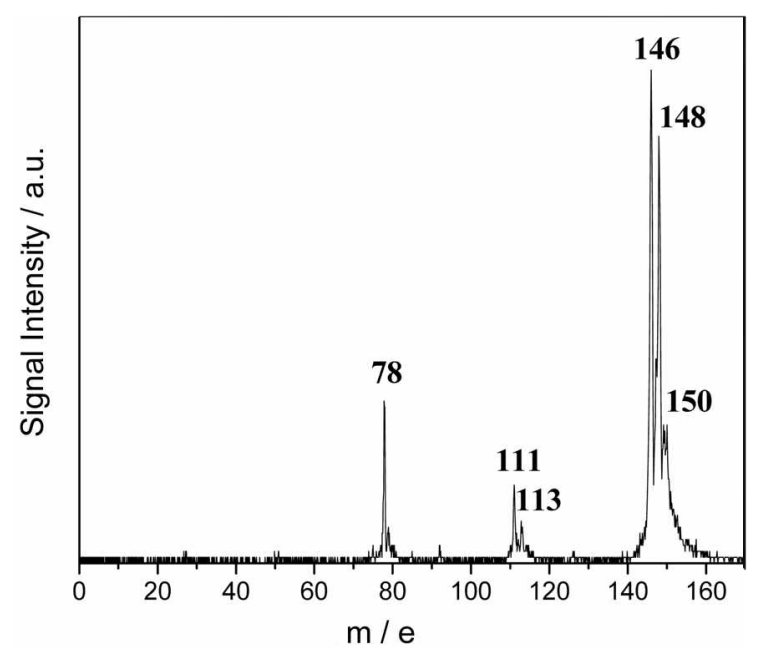

Figure 4. TOF mass spectrum of 1,4-DCB at 248 nun.

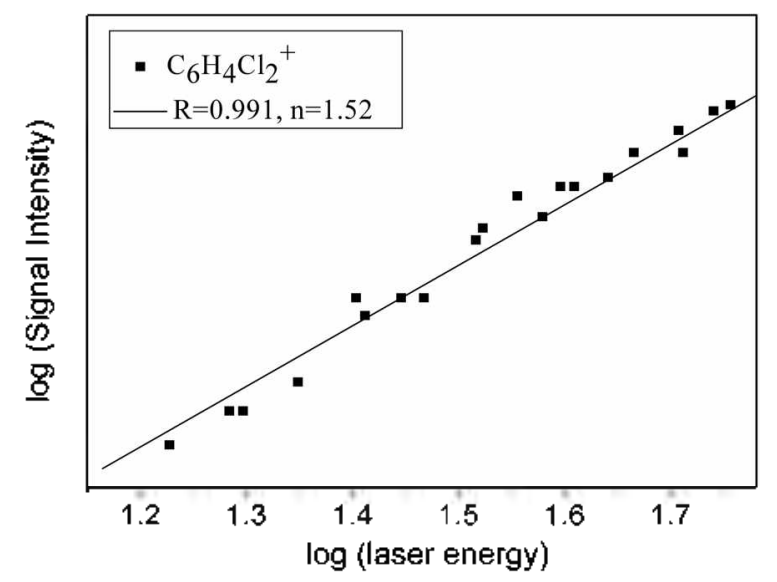

Figure 5. The relationship between laser energy and signal intensity of $\mathrm{C}_{6} \mathrm{H}_{4}{ }^{35} \mathrm{Cl}_{2}^{+}$at $248 \mathrm{~nm}$.

signal intensity of the molecular ion $\left(\mathrm{C}_{6} \mathrm{H}_{4}{ }^{35} \mathrm{Cl}_{2}{ }^{+}, \mathrm{m} / \mathrm{e}=146\right)$ at different sample concentrations and a laser intensity of $248 \mathrm{~nm}$. We prepared 1,4-DCB sample gases at six different concentrations in the ppmV/N range. Figure 6 shows the relationships between the concentration of $1,4-\mathrm{DCB}$ and the signal intensity of $\mathrm{C}_{6} \mathrm{H}_{4}{ }^{35} \mathrm{Cl}_{2}{ }^{+}(\mathrm{m} / \mathrm{e}=146)$ at $248 \mathrm{~nm}$.

The relationship between the ion signal of $\mathrm{C}_{6} \mathrm{H}_{4}{ }^{35} \mathrm{Cl}_{2}{ }^{+}$(M $=146$ ) and the sample concentration was close to a linear one in the ppmV/V range. We were able to achieve the detection limit of our instrument, according to the method of Williams, from a TOF mass spectrum of the naphthalene permeation standard." The detection limit $d$ is calculated according to the formula

$$
d=\frac{c}{p-\bar{m}} 2 \sigma
$$

In this formula the variance $\sigma$ was the noise level between the mass peaks, $\bar{m}$ is the mean value of the noise as a baseline. The variance $p$ is the signal peak height of the target molecular in the mass spectrum, $\mathrm{c}$ is the concentration of $1,4-\mathrm{DCB}$. The mass spectrum obtained at $266 \mathrm{~nm}$ is

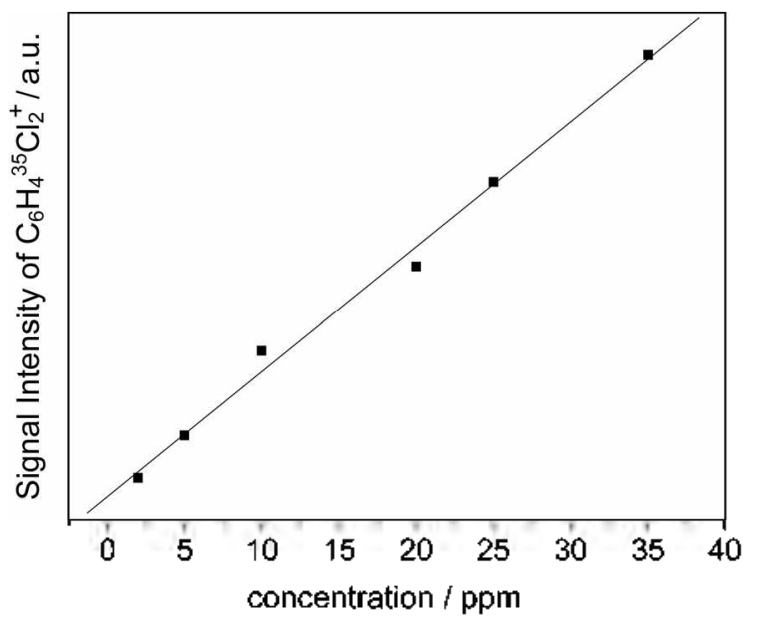

Figure 6. Linear variation between 1,4-DCB concentration and ion singal intensity. 


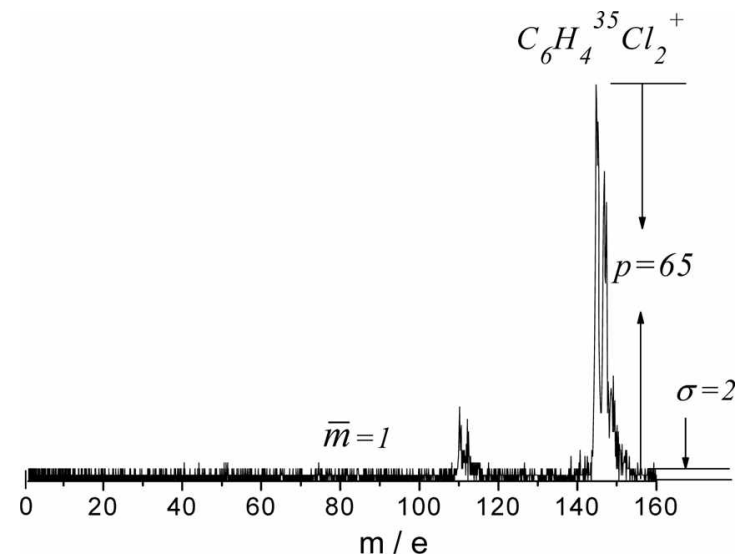

Figure 7. Mass spectrum of $1,4-\mathrm{DCB}$ at 248 nun (the concentration is 2 ppin, $c=2$ ppm).

shown in Figure 7 where the concentration was $2 \mathrm{ppm}$. The detection limit of $1,4-\mathrm{DCB}$ at $248 \mathrm{~nm}$ is about $125 \mathrm{ppbV} / \mathrm{V}$.

\section{Conclusion}

In this paper we reported on the multiphoton jonization characteristics of 1,4-dichlorobenzene excited by a tunable dye laser output in the wavelength range from $240 \mathrm{~nm}$ through to $250 \mathrm{~nm}$. The repetition of the laser is $10 \mathrm{~Hz}$ with about a $25 \mathrm{~mJ}$ energy and a $8 \mathrm{~ms}$ duration. To reduce thee condensation effects at room temperature, a special heatable sample inlet system with an effusive nozzle was constructed to introduce a semi-volatile compound into the ionization region of TOFMS. In the experiment, different concentrations of a sample were prepared and analyzed. Typically, $\mathrm{C}_{6} \mathrm{H}_{4} \mathrm{Cl}_{2}{ }^{+}$(146, 148 and $150 \mathrm{amu}$ ), $\mathrm{C}_{4} \mathrm{H}_{4} \mathrm{Cl}^{\prime}$ (111 and 113 amu) and $\mathrm{C}_{1} \mathrm{H}_{6}$ ( $78 \mathrm{amu}$ ) were the major jons generated through the multiphoton process. The relation between the jon current of $\mathrm{C}_{4} \mathrm{H}_{4}{ }^{35} \mathrm{Cl}_{3}^{+}(\mathrm{M}=146)$ and the sample concentration was close to a linear one in the ppmV $N$ range, which led to a limit of detection (LOD) of $125 \mathrm{ppb}(\mathrm{S} / \mathrm{N}=2)$ for 1,4-dichlorobenzene at $248 \mathrm{~nm}$.

\section{References}

I. Blumenstock, M.; Zimmermann, R.; Ketchup, A. Chenosphere. $2001,42,507$.

2. Oberg. T; Neuer-Etscheidt, K.; Nordsieck, H. et al. Organtohalogen Conpotinds 2002, 59.37.

3. Boesl, U. J. Mass Spectrom. 2000, 35, 289.

4. Guilhaus, M.; Mlynski, V.; Selby, D. Rapid Comm. Int, Mass Spectrometry 1997, 11,951 .

5. Rodgers, R. P.; Lazar, A. C.; Reilly, P. T. A. et al. Anal. Chent. $2000,72,5040$.

6. Morrical, B. D.; Zenobi, R. Atnosphere Environment 2002, 36. 801 .

7. Maguhn, J.; Karg, E.; Kettrup, A. et al. Environ. Sci. Technol. $2003,37,4761$.

8. Tembreull, R.; Sin, C. H.; Li, P. et al. Anal. Chem. 1985, 57 , 1186.

9. Sanda, W. D.; Moore, R. J. Phys. Chem. 1989, 93, 101.

10. Anno, T.; Matubara, I. J. Chem. Phys. 1955, 23, 796.

I1. Heger, H. J.; Zimmermann, R.; Dorfner, R, et al. Anal. Chem. $1999,71,46$. 